\title{
Long-period unstable gravity-waves and associated VHF radar echoes
}

\author{
R. M. Worthington, L. Thomas \\ Department of Physics, University of Wales, Aberystwyth, Dyfed, SY23 3BZ, UK \\ Received: 3 September 1996 / Revised: 4 December 1996 / Accepted: 6 December 1996
}

\begin{abstract}
VHF atmospheric radar is used to measure the wind velocity and radar echo power related to longperiod wind perturbations, including gravity waves, which are observed commonly in the lower stratosphere and tropopause region, and sometimes in the troposphere. These wind structures have been identified previously as either inertia-gravity waves, often associated with jet streams, or mountain waves. At heights of peak wind shear, imbalances are found between the echo powers of a symmetric pair of radar beams, which are expected to be equal. The largest of these power differences are found for conditions of simultaneous high wind shear and high aspect sensitivity. It is suggested that the effect might arise from tilted specular reflectors or anisotropic turbulent scatterers, a result of, for example, Kelvin-Helmholtz instabilities generated by the strong wind shears. This radar power-difference effect could offer information about the onset of saturation in long-period waves, and the formation of thin layers of turbulence.
\end{abstract}

\section{Introduction}

Long-period wind perturbations, often identified as gravity waves, are commonly detected in the lower stratosphere; their characteristics have been measured by both VHF radar (e.g. Cornish and Larsen, 1989; Thomas et al., 1992; Cho, 1995; Yamanaka et al., 1996) and balloons (e.g. Thompson, 1978). This study examines their influence on the echo power from VHF radar transmissions and, in particular, the imbalances between the echo powers of a symmetric pair of radar beams. Earlier radar studies, e.g. Röttger et al. (1990), have reported evidence of tilted anisotropic scattering-reflect-

Correspondence to: R. M. Worthington ing layers associated with gravity waves, and the effects of these tilted layers on radar echo power, in different radar beams, might provide useful information about both the dynamics of long-period waves and radar scattering mechanisms. Data is supplied by the MST (mesosphere-stratosphere-troposphere) radar system at Aberystwyth $\left(52.4^{\circ} \mathrm{N}, 4.1^{\circ} \mathrm{W}\right)$, using velocity and echo power measurements from radar beams at zenith angles of $\pm 12^{\circ}, \pm 6^{\circ}$ and $0^{\circ}$ (vertical), in a vertical plane aligned in a roughly NW-SE azimuth (actually $\mathrm{N} 62.3^{\circ} \mathrm{W}-$ $\mathrm{S} 62.3^{\circ} \mathrm{E}$ ). The system operates at a frequency of 46.5 $\mathrm{MHz}$, with a peak power of $160 \mathrm{~kW}$ and a duty cycle of about $2.5 \%$; the square, phased antenna array of 400 four-element Yagis occupies an area of $1.1 \times 10^{4} \mathrm{~m}^{2}$, and provides a one-way beamwidth of $3^{\circ}$. The transmissions use $8 \mu$ s pulses, coded with a baud length of $2 \mu$ s for a height resolution of $300 \mathrm{~m}$, and the receiver samples at $1 \mu$ s intervals. Each cycle of beam directions takes $2.4 \mathrm{~min}$. The horizontal separation of the beams is $2.1 \mathrm{~km}$ for a $6^{\circ}$ beam pair at a height of $10 \mathrm{~km}$.

\section{Tilted scattering layers and radar echoes}

VHF atmospheric radar operates by detecting the backscatter or reflection of radar pulses from perturbations of air refractivity. The echo power of the pulses returned from a region of atmosphere generally depends on the zenith angle at which the radar beam is pointing, an effect known as 'aspect sensitivity'; the power is usually highest using a vertically pointing radar beam, and falls off as the zenith angle of the beam increases. Two common models for this effect invoke either anisotropic turbulence, or partial reflection from the thin, stable horizontal layers which have been observed in temperature measurements from balloon soundings with high vertical resolution (e.g. Dalaudier et al., 1994; Luce et al., 1995). The latter study suggests that partial reflection from these layers may be the dominant source of radar returns in a vertical beam. Gage et al. (1981) compared the wind velocity and echo power measured in 
a vertical radar beam while a short-period monochromatic gravity wave (period $\sim 18 \mathrm{~min}$ ) was observed. Variations of echo power were interpreted in terms of the gravity wave tilting the anisotropic scattering layers or 'horizontal laminae'; the highest echo power occurred at those phases of the wave when the vertical beam was perpendicular to the layers. More recently, aspect sensitivity has been attributed by Tsuda et al. (1997b) to the distribution of tilt angles of the 'reflection layers', when they are displaced from the horizontal by a spectrum of gravity waves.

Descriptions of radar echo power generally assume a dependence on zenith angle, but not on azimuth angle (e.g. Hooper and Thomas, 1995). However, perturbations of the echo powers, varying with azimuth, could be caused by tilting of the anisotropic scattering layers or spatial variations over the distance between the radar beams. Tsuda et al. (1997a) investigated the azimuth dependence of echo power, using radar beams in steps of $30^{\circ}$ azimuth, with a constant $6^{\circ}$ zenith angle. The azimuthal variations of echo power, typically up to $5 \mathrm{~dB}$, were attributed to the tilting of layers by a monochromatic gravity wave. Spaced antenna (SA) radar systems are also used to investigate tilted scattering layers, since direct measurements of 'angle of arrival' are possible (Larsen and Röttger, 1991). Tilt angles up to $1-2^{\circ}$ have been reported using this method (Röttger et al., 1990; Larsen and Röttger, 1991; Palmer et al., 1991, 1993; Van Baelen et al., 1991; Brown et al., 1995) and these will also introduce an error into wind measurements in the vertical direction. Röttger et al. (1990) and Palmer et al. (1993) relate these tilts to gravity-wave activity, and Röttger et al. (1990) suggest, in particular, mountain waves or inertia-gravity waves as a probable cause. However, with a Doppler-beam-swinging (DBS) system such as the Aberystwyth MST radar, direct measurements of these tilt angles are not available. In-situ measurements of temperature structure by Dalaudier et al. (1994) also report some evidence that the layers or 'sheets' are tilted, although the horizontal extent of their measurements was limited.

The relation between echo powers in radar beams pointing at different zenith angles (e.g. $\left.0^{\circ}, 6^{\circ}, 12^{\circ}\right)$ is very variable over time scales of days or hours, and over short vertical distances (Hooper and Thomas, 1995). In a symmetric pair of radar beams, e.g. one pointed toward the north at a zenith angle of $6^{\circ}$ and the other at $6^{\circ}$ toward the south, the Doppler shifts of the received pulses would usually be of opposite sign; however, provided the atmosphere is horizontally uniform over scales much larger than the separation of the beams, and there are no errors in the radar height-ranging or calibration, then symmetry should imply that the echo powers in these two beams are equal. If the anisotropic scattering layers are instead tilted, one beam will point more nearly perpendicular to the layers, and the other will point even further from the perpendicular direction. This could, therefore, introduce an imbalance in the echo powers measured by symmetric beams.

\section{Observations}

Figures 1 and 2 show two case studies, the datasets for 7-8 March 1994 and 13-14 April 1996. They each show: perturbations of echo power, measured by four beams (zenith angles $\pm 6^{\circ}, \pm 12^{\circ}$ ) aligned in a vertical plane with a roughly NW-SE azimuth; the differences between the echo powers in $\mathrm{NW}^{\circ}$ and $\mathrm{SE}^{\circ}$ beams, and similarly for $\mathrm{NW} 12^{\circ}$ and $\mathrm{SE} 12^{\circ}$; and the component of horizontal wind velocity in the NW-SE direction given by

$\mathrm{U}_{\mathrm{NW}-\mathrm{SE}}=\frac{r_{+\theta}-r_{-\theta}}{2 \sin \theta}$

where $r_{+\theta}$ and $r_{-\theta}$ are radial wind velocities measured by beams at zenith angles of $+\theta$ and $-\theta$ in the NW-SE azimuth. All the plots are filtered to retain vertical wavelengths less than $5 \mathrm{~km}$ and wave periods longer than $6 \mathrm{~h}$, using 4th order Butterworth filters; these remove the background component and the higherfrequency variations of wind velocity and echo power.

The perturbations of echo power, in plots $a, b, e, f$ of Figs. 1 and 2, each show a clear band of increased power near $11-12 \mathrm{~km}$, due to the sharpness of the tropopause near that height (Hooper and Thomas, 1995). The plots also show many other structures in both the troposphere and stratosphere, most of which cancel out when the echo powers in the symmetric beams are subtracted from each other, in plots c, g of Figs. 1 and 2. In Fig. 1, the cancellation is almost exact in the troposphere, while some structures remain in the stratosphere; in Fig. 2, a more typical example, the power differences are often smaller and the change between troposphere and stratosphere is less marked.

The origin of long-period variations of horizontal wind, as shown in d, h of Figs. 1 and 2, is still a subject of controversy (e.g. Hines, 1989; Cornish and Larsen, 1989; Hines, 1995; Larsen, 1995). Inertia-gravity waves and mountain waves can sometimes appear difficult to distinguish (e.g. Hines, 1989, 1995), and the stratospheric horizontal wind stuctures in d, h of Figs. 1 and 2 do not show any clear, persistent phase descent (or ascent) with time that would allow identification of a monochromatic inertia-gravity wave (e.g. Thomas et al., 1992). The vertical-wind measurements for the two datasets are presented in Fig. 3b, d in order to show any evidence of mountain-wave activity. The case study in Fig. $3 \mathrm{~b}$ contains large-amplitude oscillations of vertical wind velocity with height, similar to the mountain-wave observations of Worthington and Thomas (1996a), whereas that in Fig. 3d shows much less activity. The horizontal wind vectors in Fig. 3a, c both show high wind speeds, approaching $50 \mathrm{~ms}^{-1}$ at some heights, but the low-level wind is weaker in Fig. 3c, which is consistent with the relative absence of mountain waves in Fig. 3d. Whatever the origin of the wavelike structures, only their associated wind shears are examined further in Sect. 4 and 5.

Profiles based on 1-h sections of the horizontal wind, power difference, and echo power data, using various beams, are plotted in Figs. 4 and 5a,b. A wind velocity towards NW is defined as positive, and the power 

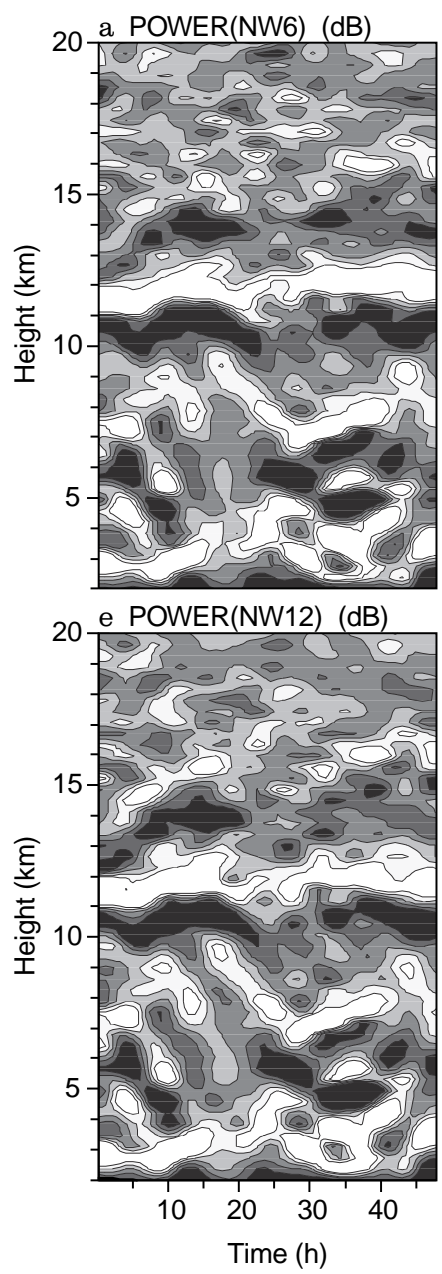

Fig. 1a-h. Perturbations of the radar echo power in the a NW6 $6^{\circ} \mathbf{b}$

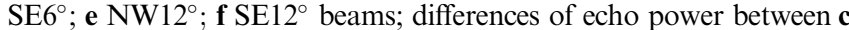
$\mathrm{NW}^{\circ}$ and $\mathrm{SE}^{\circ}$; $\mathrm{g} \mathrm{NW} 12^{\circ}$ and $\mathrm{SE} 12^{\circ}$ beams; horizontal wind velocity perturbations in the NW-SE direction, measured by $\mathbf{d ~ N W} 6^{\circ}$ and $\mathrm{SE}^{\circ} ; \mathbf{h} \mathrm{NW} 12^{\circ}$ and SE12 ${ }^{\circ}$ beam pairs. A wind velocity toward

difference refers to the NW echo power minus the SE. Figures 4 and $5 \mathrm{a}$ use sections with the largest wind shears and power differences taken from the datasets represented in Figs. 1, 2; Fig. 5b is taken from the dataset 2 November 1994, considered by Worthington and Thomas (1996b) in connection with the possible effects of tilted layers on velocity and momentum flux measurements. Standard errors on the profiles of velocities, power differences, and powers are less than $0.5 \mathrm{~m} \mathrm{~s}^{-1}, 1.3 \mathrm{~dB}$ and $0.9 \mathrm{~dB}$ respectively. The wind shears in the stratosphere often approach $\pm 20 \mathrm{~m} \mathrm{~s}^{-1} \mathrm{~km}^{-1}$, the approximate values to maintain shear instability, when the Richardson number falls to 1 if a typical BruntVäisälä frequency $\left(0.02 \mathrm{rad} \mathrm{sec}^{-1}\right)$ is assumed. The power differences presented in Figs. 4, 5a, b are not filtered in height and show that, although there is often an offset of +1 or $2 \mathrm{~dB}$, there are superimposed variations of larger magnitudes. The phase of these power difference variations is always displaced by about $\frac{1}{4}$ cycle from the velocity oscillations, i.e. the largest power differences correspond to the maximum wind shears, and not the
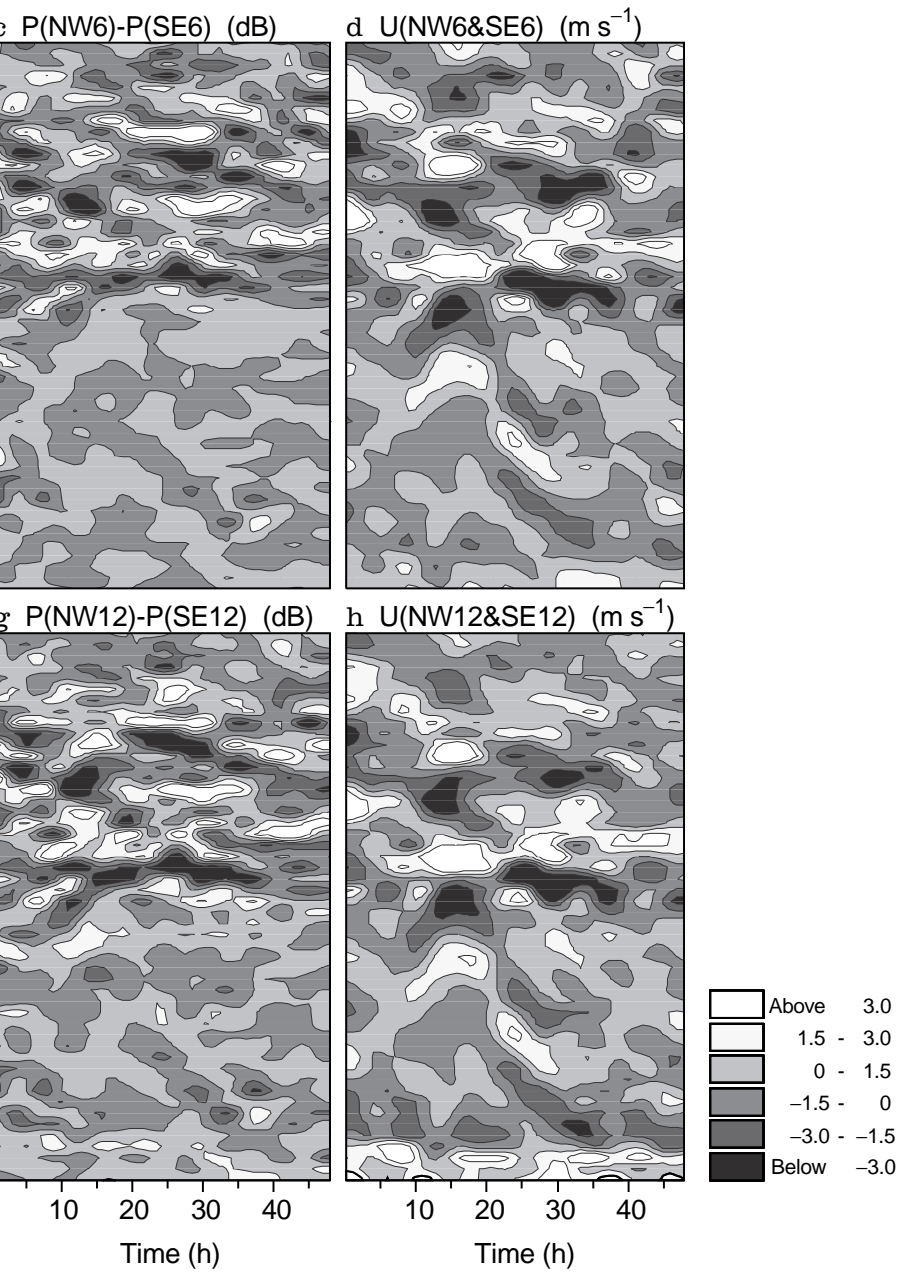

NW is defined as positive. The dataset is 7-8 March 1994, and all the plots are filtered to retain vertical wavelengths less than $5 \mathrm{~km}$ and periods greater than $6 \mathrm{~h}$. All the plots use the same contour scale, with the appropriate units shown for each. The tropopause is near 10.5$11.5 \mathrm{~km}$

maximum wind velocities. The sign of the power difference also alternates, with a negative power difference linked to a positive wind shear, and vice versa; Fig. 4 shows these relations clearly over at least two cycles in the vertical. Since the power differences appear to be genuine, and related to the phase of the longperiod wave, the question arises whether the suggested 'tilted layers' should be more likely at certain phases of the long-period wave.

\section{Influence of wind shear and aspect sensitivity}

An explanation of the 'power differences' observed in the present study in terms of tilted aspect-sensitive layers requires that these regions of the atmosphere simultaneously show high aspect sensitivity. In Fig. 5b, the wind shears at 10.5 and $13.5 \mathrm{~km}$ are the same sign and gradient (approximately $-20 \mathrm{~m} \mathrm{~s}^{-1} \mathrm{~km}^{-1}$ ), but the lower wind shear is associated with no power difference, and the upper one with a large power difference. The decrease in 

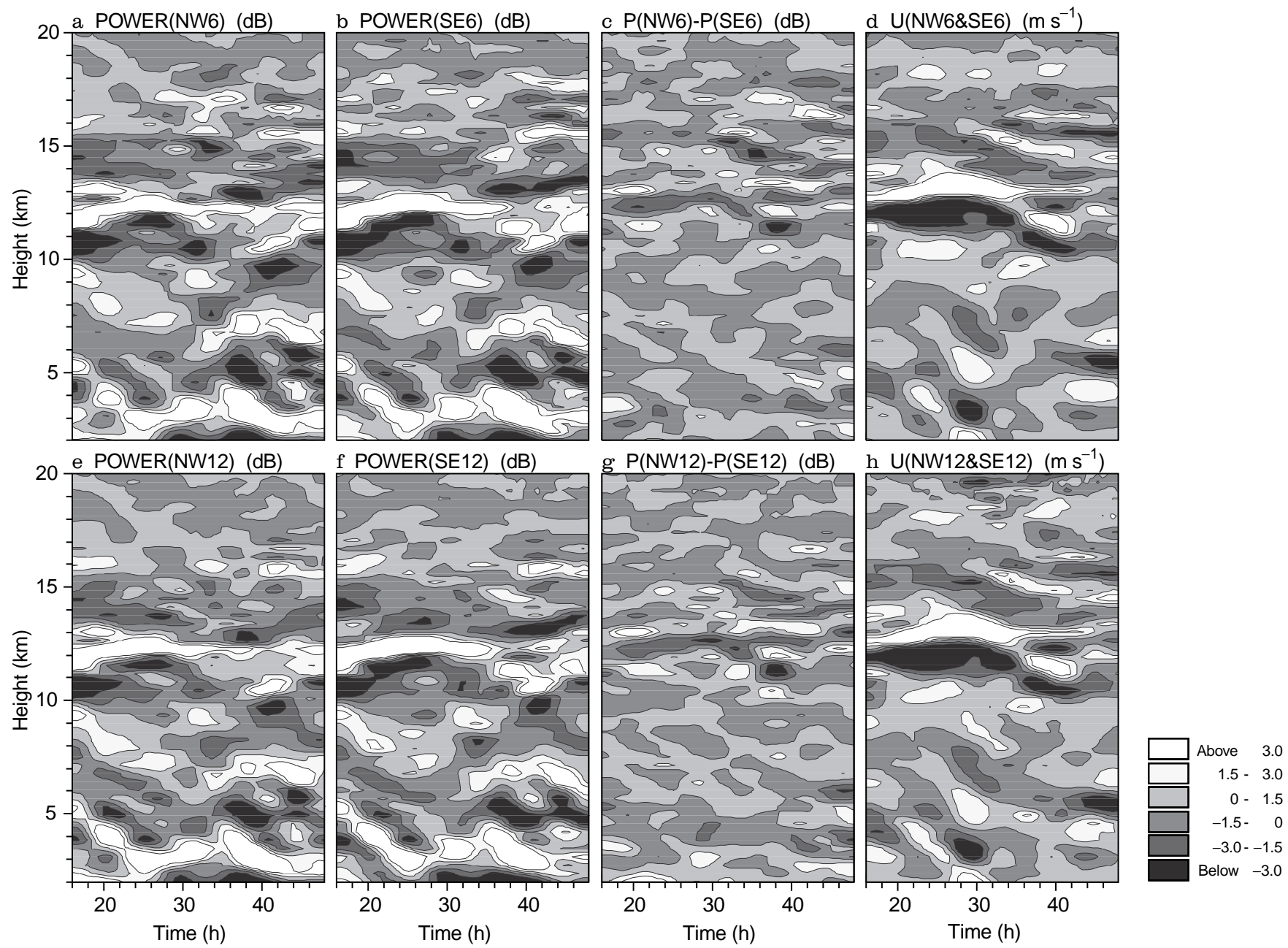

Fig. 2a-h. As Fig. 1, for the dataset 13-14 April 1996. The tropopause is near 11-12 km

echo power between $0^{\circ}$ and $12^{\circ}$ beams is approximately 7 $\mathrm{dB}$ for the lower case and $25 \mathrm{~dB}$ for the upper; i.e. the wind shear seems to be associated with large power differences only when aspect sensitivity is strong.
The dependence of power difference on both wind shear and aspect sensitivity is examined further in Fig. 6. Data from over 40 days of measurements, using the height range 5-17 km, are categorised into 'high',

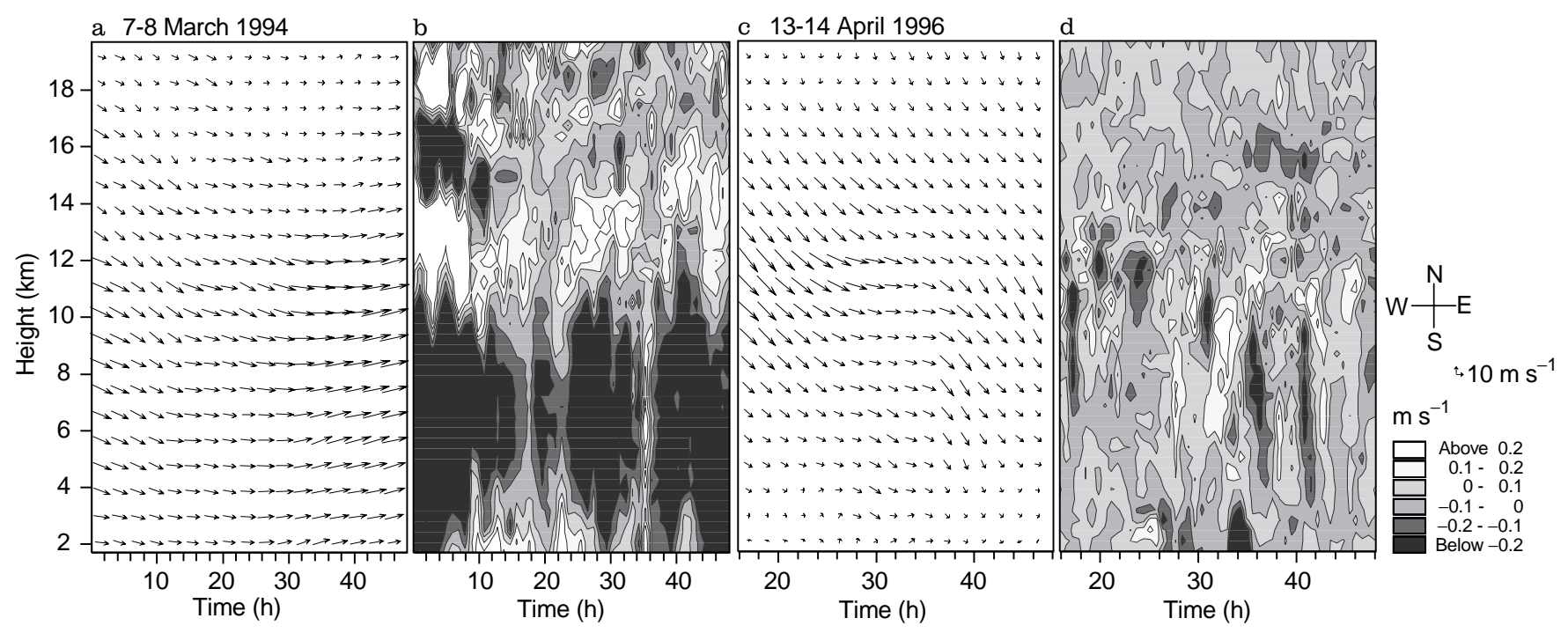

Fig. 3a-d. Height-time plots of background wind vectors and vertical velocity contours for the two datasets used in Figs. 1 and 2 


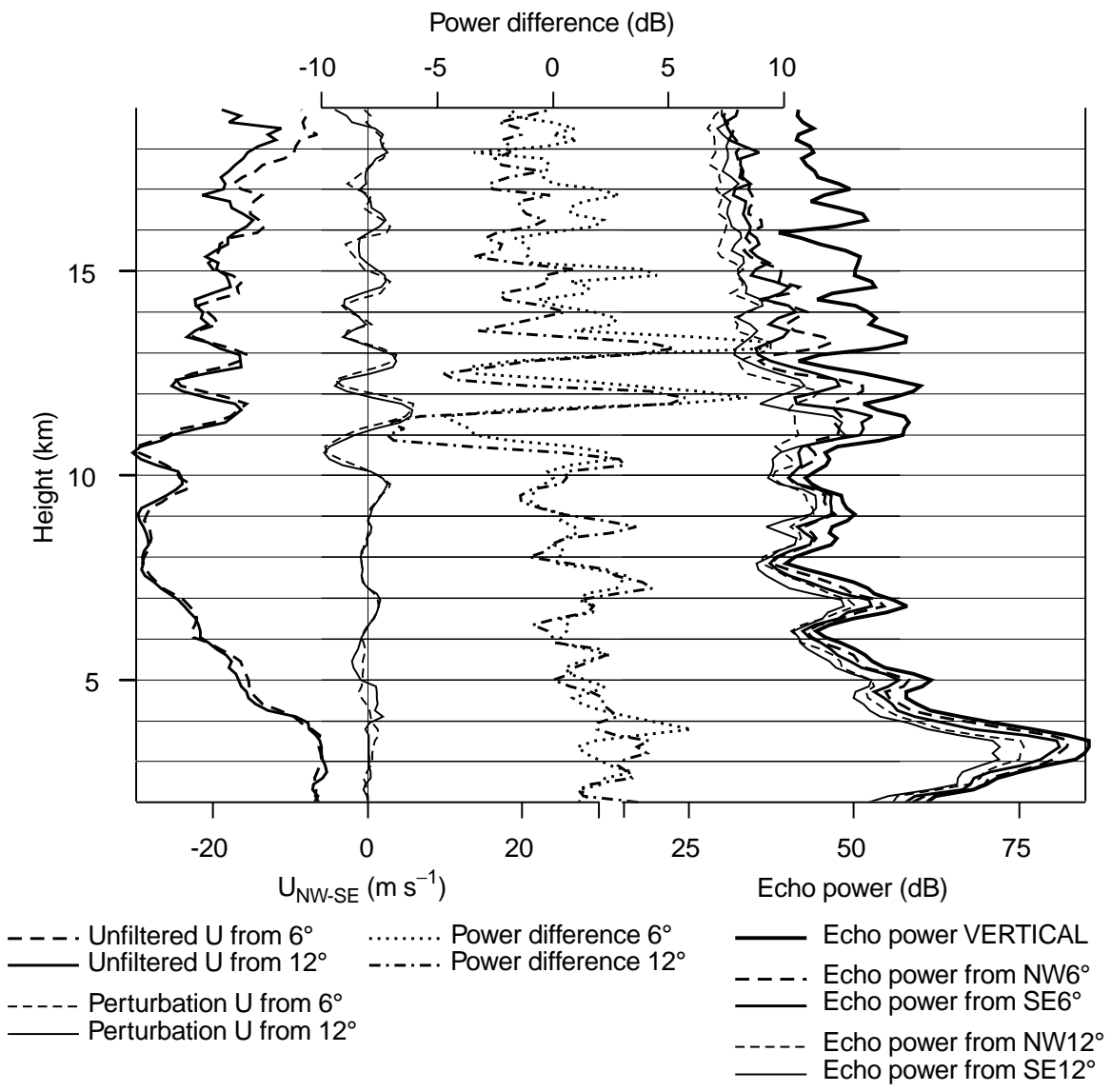

Fig. 4. Profiles of: wind velocity in the NW-SE direction (total, and filtered to remove the background wind and periods less than $6 \mathrm{~h}$ ); the unfiltered power differences between $\mathrm{NW}^{\circ}$ and $\mathrm{SE} 6^{\circ}$, and $\mathrm{NW} 12^{\circ}$ and $\mathrm{SE} 12^{\circ}$ beams; unfiltered echo powers for vertical, NW6 ${ }^{\circ}, \mathrm{SE}^{\circ}$, $\mathrm{NW} 12^{\circ}$ and $\mathrm{SE} 12^{\circ}$ beams. The data are averaged over $1 \mathrm{~h}, 1330-1430$ GMT 14 April 1996 'medium' and 'low' aspect sensitivity, based on the decrease in echo power between the vertical beam and the average of the two $12^{\circ}$ beams. The upper and lower $1 \%$ of data points are discarded, and the remainder divided into three parts containing approximately equal numbers of points: 4-12 dB (low aspect), 12-18 dB (medium) and 18-27 dB (high). Data is filtered as for Figs. 1 and 2, and averaged into $1 \mathrm{~h}$ sections. The wind shear is evaluated by a straight-line fit over three data points (a height interval of $300 \mathrm{~m}$ ), and will therefore underestimate the shears over smaller vertical scales. Simultaneous measurements of $N$ are not available.

The plots in Fig. 6 show that the majority of points correspond to relatively weak wind shears. Shears of $\pm 20 \mathrm{~m} \mathrm{~s}^{-1} \mathrm{~km}^{-1}$ or greater, although found in some of the examples in Figs. 4 and 5, are relatively uncommon in these plots. Figures $6 a, c$, e and b, d, f suggest that a given wind shear produces largest power differences when the aspect sensitivity is high; again, negative shears correspond to positive power differences, and vice-versa. However, Fig. 6 also shows that the relation between shear and power difference is not simply linear. For a power difference of $+4 \mathrm{~dB}$, the most probable required wind shear is near -5 to $-10 \mathrm{~m} \mathrm{~s}^{-1} \mathrm{~km}^{-1}$ in all the plots of Figs. 6a-f but, comparing Figs. 6a, b and e, f, the probability of obtaining this power difference in lowaspect conditions is only about $10 \%$ of the probability in high-aspect conditions.

The aspect sensitivity is generally lower in the troposphere than the stratosphere (Hooper and Tho- mas, 1995), so the apparent dependence of power difference on aspect sensitivity in Fig. 6 might be related only to the larger beam separation at stratospheric heights. Also, the static stability is lower in the troposphere, so the Richardson number more commonly falls low enough for the airflow to break down into turbulence (e.g. Bannon, 1950). However, when Fig. 6 is replotted with data confined to height ranges of either $5-11 \mathrm{~km}$ or $11-17 \mathrm{~km}$, individually, the same pattern emerges, i.e. the largest power differences are found in regions of high wind shear and high aspect sensitivity.

\section{Instability of long-period waves}

If the long-period structures in Figs. 1, 2 represent inertia-gravity waves, studies such as Thomas et al. (1992), Sato (1994) and Cho (1995) show that their horizontal wavelength is typically hundreds of kilometres. Since their vertical wavelength is about $2 \mathrm{~km}$, the slope of the phase fronts would be approximately $1^{\circ}$. The aspect sensitivity at beam zenith angles near $12^{\circ}$, measured in a region of high aspect sensitivity by Tsuda et al. (1997b) in their Fig. 4, is approximately $0.8 \mathrm{~dB}$ per degree so, for instance, an incidence angle increased by $1^{\circ}$ in one beam and decreased by $1^{\circ}$ in the other would produce a power difference of $1.6 \mathrm{~dB}$. This is significantly smaller than the observed power differences, which commonly approach $5 \mathrm{~dB}$, although 
a

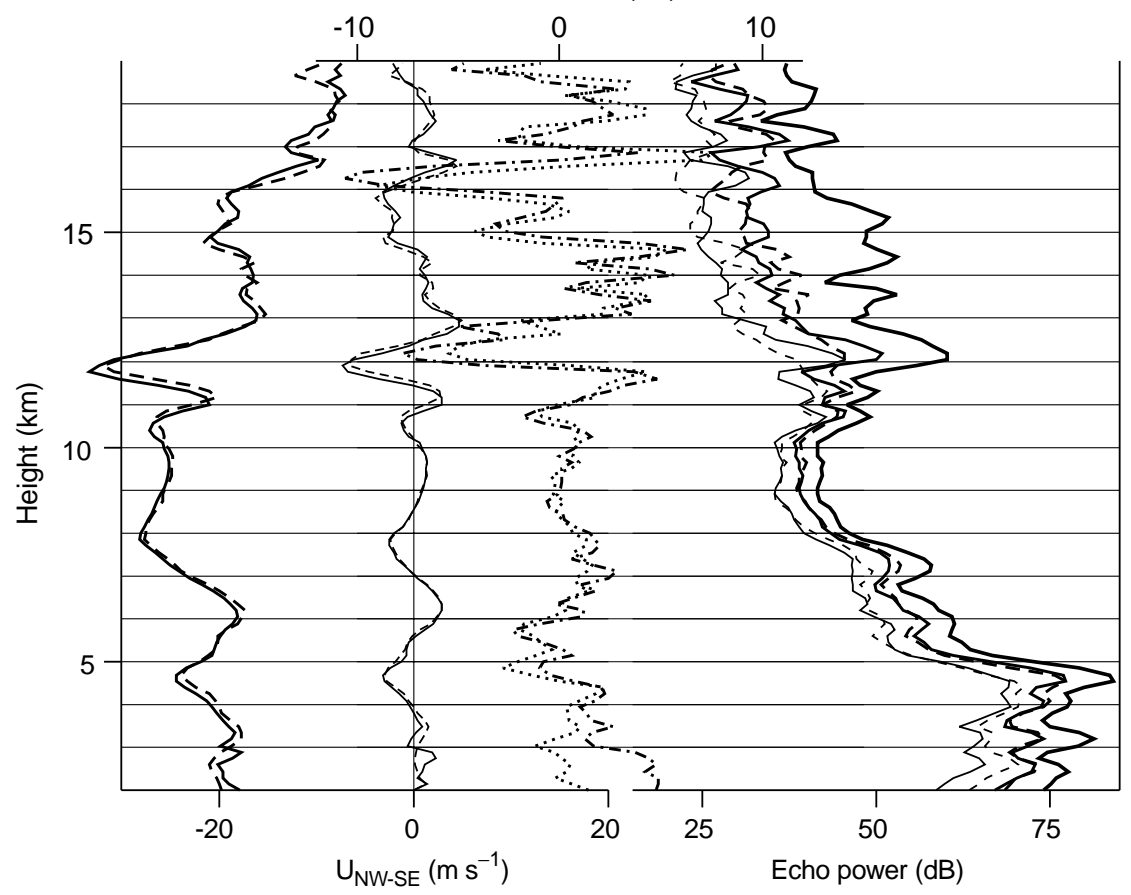

b

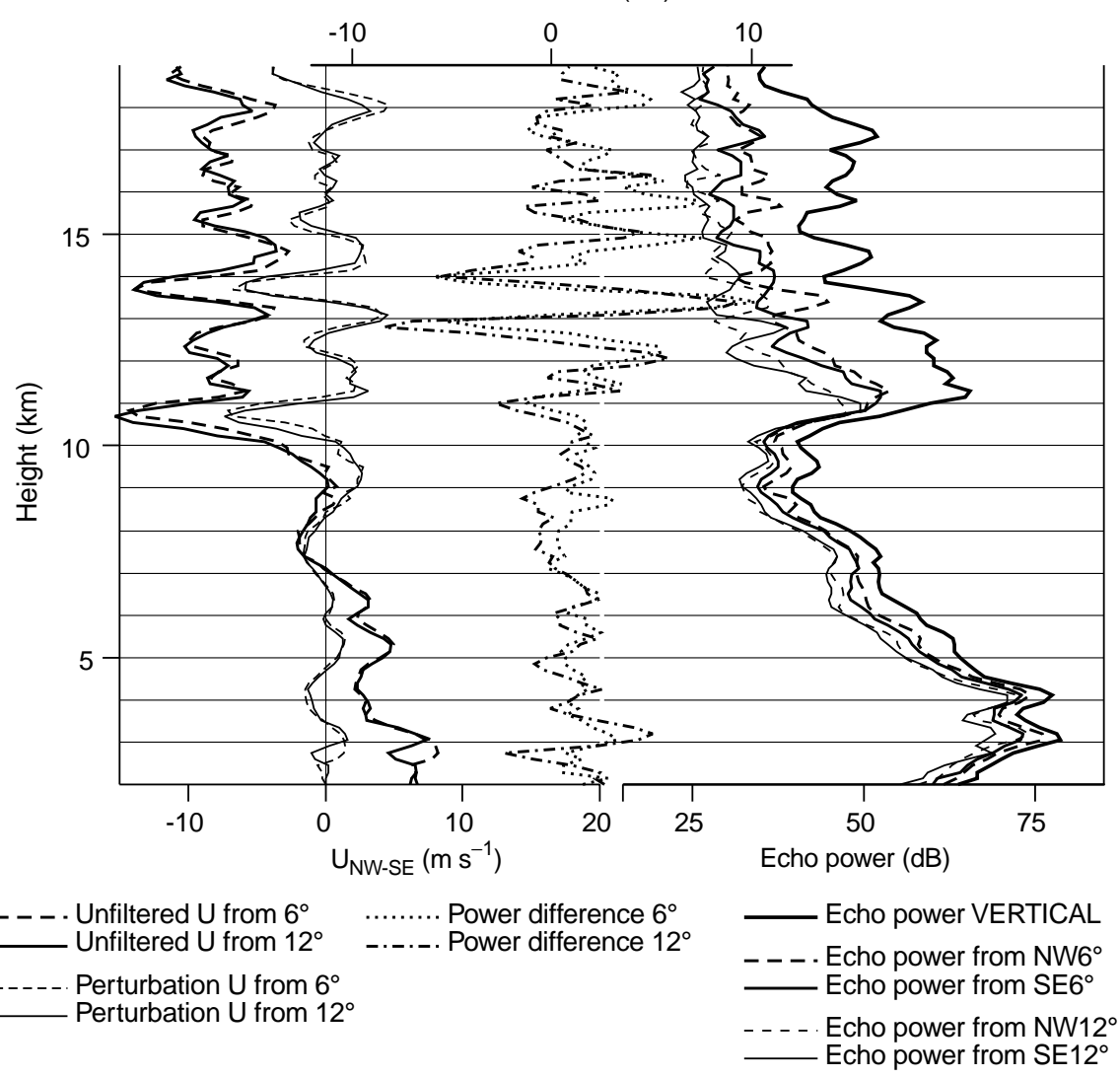

Fig. 5a, b. As Fig. 4, for a 0130-0230, 8 March 1994; b 1930-2030, 2 November 1994 the aspect sensitivity here might perhaps be greater than in their results. If tilted anisotropic scattering layers are used to explain such power differences, a mechanism is needed which generates larger tilt angles. Gage et al. (1981) and Gage (1986) describe tilted layers caused by high-frequency gravity waves, and these might affect the echo powers in radial beams; however, if the displacements are sinusoidal, any resulting power difference between symmetric beams should cancel out over time scales longer than, for example, 6 hours, as selected by the filtering in Figs. 1, 2. 

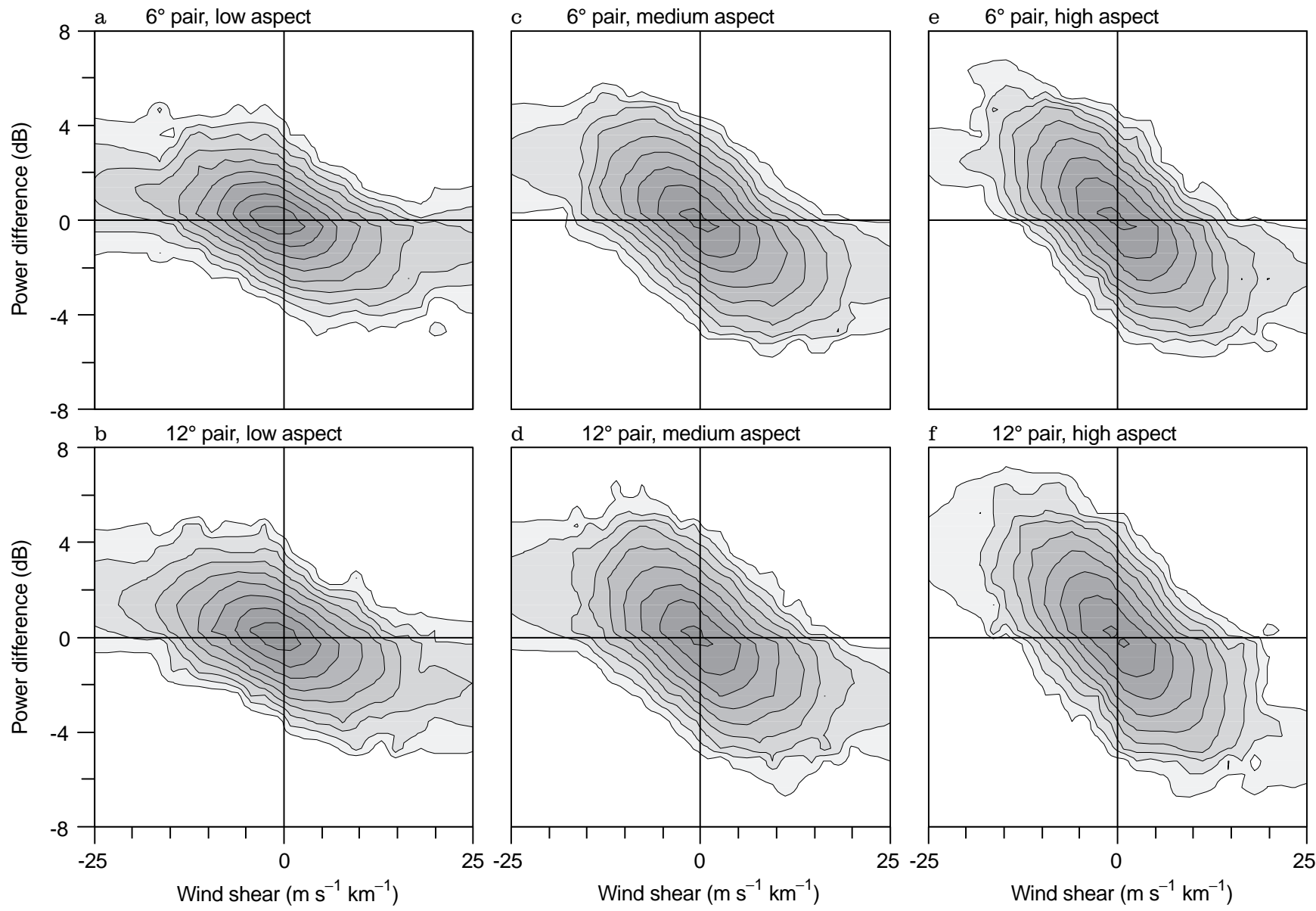

Fig. 6a-f. Dependence of power difference on the vertical shear of the horizontal wind. The data, for beam pairs at both $\pm 6^{\circ}$ and $\pm 12^{\circ}$ zenith angles, are also categorised for low, medium and high aspect

It is seen from Figs. 4 and $5 \mathrm{a}, \mathrm{b}$ that the power differences at $6^{\circ}$ and $12^{\circ}$ are fairly similar. In the partial reflection model, these similar values could be produced by layers tilted at an angle between $6^{\circ}$ and $12^{\circ}$. In practise, while the layers would be most often horizontal, a similar, significant minority could be tilted to a range of angles near $6^{\circ}$ and $12^{\circ}$, producing a similar effect on echo powers of beams with $\theta=6^{\circ}$ and $12^{\circ}$ if the layers are not first destroyed by turbulence. KelvinHelmholtz instabilities (KHI) can develop in regions of sufficiently high wind shear, and the tilt angles of their sloping surfaces typically lie in the range $0-30^{\circ}$ (Fritts and Rastogi, 1985). If fine-scale layered temperature structures which generate the radar echoes are tilted in similar fashion to the background potential temperature surfaces (e.g. Fritts and Rastogi, 1985), the most powerful radar echoes will be received from an offvertical direction, perpendicular to these tilted layers.

KHI and breaking gravity waves have been observed in the lower stratosphere by early UHF radars (e.g. Hicks, 1969; Dutton and Panofsky, 1970; Browning et al., 1970; Browning, 1971; Browning et al., 1972), instrumented aircraft (e.g. Roach, 1969; Axford, 1970, 1973; Pfister et al., 1986) and patterns in cirrus cloud (e.g. Reiter and Nania, 1964; Ludlam, 1967; Young, sensitivity. Data points are counted in bins of $1 \mathrm{~dB} \times 1 \mathrm{~m} \mathrm{~s}^{-1} \mathrm{~km}^{-1}$; the outer contour line corresponds to 2 points per bin, and the density of points doubles at every inner contour line
1971; Hill, 1951), generally in regions of high wind shear, and also in the mesosphere by Reid et al. (1987). KHI in the troposphere are commonly revealed by billow-cloud formations (e.g. Ludlam, 1967; Bader et al., 1995). Turbulent layers in the stratosphere are described by Sato and Woodman (1982) and Tsuda et al. (1985), and Kilburn et al. (1995) observe thin, turbulent, aspect sensitive layers, closely related to the wind shear and attributed to KHI breaking. Klostermeyer and Rüster (1981) interpret variations of VHF echo power in a $\theta=12.5^{\circ}$ radar beam, with a period of a few minutes and amplitude up to $20 \mathrm{~dB}$, to be caused by tilted specular layers or enhanced turbulence linked to KHI. Röttger and Schmidt (1979) use a VHF radar to detect the fine structure of KHI in echo-power measurements near a height of $4.5 \mathrm{~km}$. An impression of the development of tilted structures caused by wave breaking or KHI development, from Browning and Watkins (1970), is reproduced in Fig. 7a. The KHI would have periods much shorter than the $6 \mathrm{~h}$ low-pass cutoff used when filtering the radar data, and vertical and horizontal scales much smaller than those of the long-period waves which might generate them. The radar measurements, with a height resolution of $300 \mathrm{~m}$ and time resolution of $2.4 \mathrm{~min}$, will often be too crude to resolve the structure 


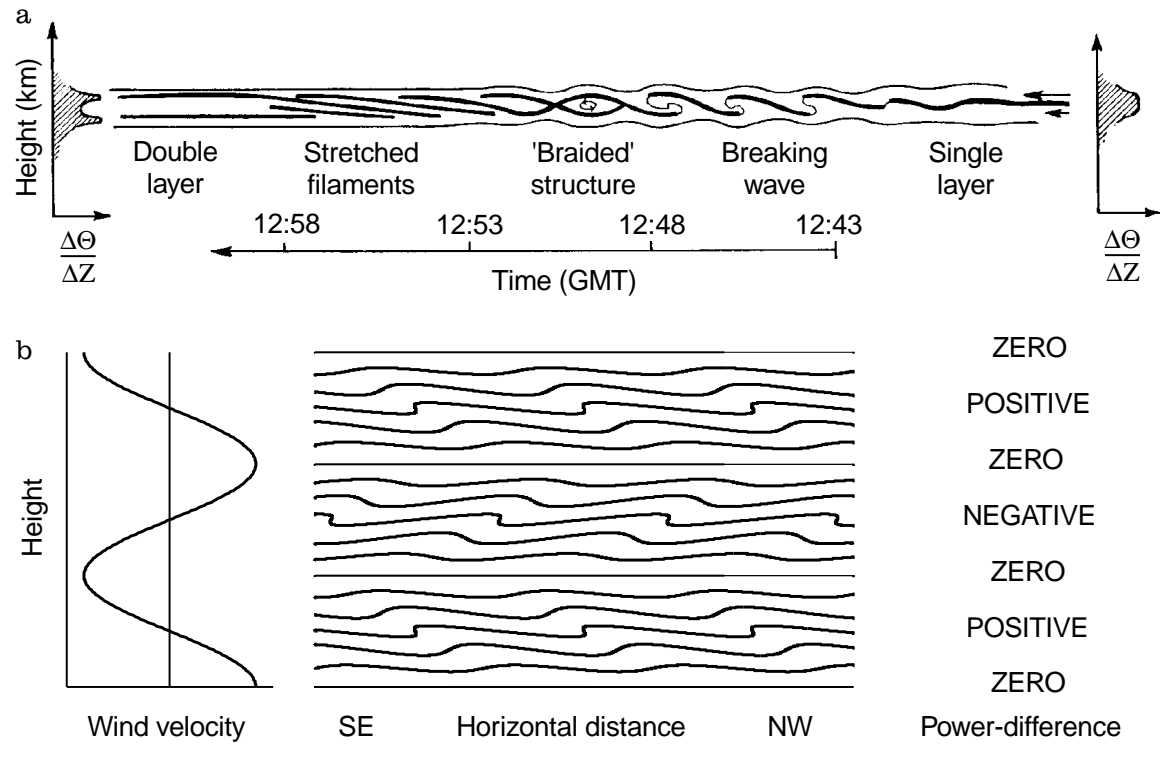

Fig. 7a, b. a Schematic representation of various stages in the development of Kelvin-Helmholtz instability, showing the formation of tilted structures, after Browning and Watkins (1970). b Model of tilted layers to explain the powerdifference effects in Figs. 1, 2, 4, 5. Left panel: profile of the horizontal velocity of the long-period wave; Centre panel: cross section of the scattering layers, in the same vertical plane as the wave velocity plot. Right panel: variations of power difference between $+\theta$ and $-\theta$ beams, as expected from the tilt angles of the anisotropic scattering layers of individual layers or KHI. However, since the wind shears are present for many hours, and the resulting $\mathrm{KHI}$ at a given height would, statistically, tend to slope in a constant direction and produce power differences of the same sign, an imbalance of mean echo power in beams at zenith angles $\pm \theta$ could then emerge.

A summary of the 'tilted layer' model is shown in Fig. 7b. The sign of the wind shear reverses with each half-cycle of the long-period wave, and the sloping direction of the tilted layers also reverses. Real KHI would not be expected to be as monochromatic as in Fig. $7 \mathrm{~b}$ but might still, over several hours, produce an imbalance in the echo powers of a pair of beams which changes sign with every half-cycle in height as shown in Figs. 4, 5. The power differences and wind shears observed at different heights in Figs. 4, 5 are out of phase by a half cycle, and not in phase i.e. the sign of the power difference is consistent with such a model.

Measurements by Yoe et al. (1994) report that the radar backscatter is usually most aspect sensitive for beams aligned parallel to the azimuth of the horizontal wind, when the jet stream is nearby. However, recent measurements using spaced antennas have reported that, in thin regions of high wind shear, the radar backscatter is most aspect sensitive transverse, rather than parallel, to the wind (Brown et al., 1995, 1996). This is interpreted as evidence for 'fine rolls' within the shear layers (Brown et al., 1996), apparently consistent with the KHI in layers of high wind shear that are invoked here to explain the power differences between symmetric beams in Figs. 1, 2, 4 and 5. Clodman (1957) investigated regions of high-level turbulence using aircraft, and suggested that the 'bumpiest' flights occurred while flying parallel or anti-parallel to the wind direction, and the smoothest when flying perpendicular to the wind. This study was based only on pilots' comments, and the interpretation was uncertain; however, the observations could be consistent with the 'rolls' inferred by Brown et al. (1996).
If the echo power differences do indicate the occurrence of shear instability, it appears that KHI are more common than is suggested by visual observations of billow clouds. Also, the heights in the lower stratosphere where power differences, in this study, suggest that KHI are particularly common, are actually those where their detection previously, in cloud patterns or using UHF radar, has been least likely due to the low humidity, and weakness of UHF radar returns. The common occurrence of KHI in the lower stratosphere could be relevent to the suggestion of O'Sullivan and Dunkerton (1995) that Kelvin-Helmholtz instabilities of inertia-gravity waves may be one of the most important mechanisms for cross-isentropic transport and vertical mixing of constituents in the lower stratosphere. The possible importance of KHI for dispersion of air pollutants emitted by aircraft has been evaluated by Schilling and Janssen (1992).

There may be other explanations for the power difference observations, some other mechanism which could introduce an asymmetry in the echo powers of symmetric beams. However, it appears unlikely that the effect is an artefact of the radar system or processing, since the echo powers of symmetric beams cancel out in the troposphere in Fig. 1, while the pattern which emerges in the stratosphere is closely linked to the longperiod wind shear when aspect sensitivity is high. The relation between velocity and power difference is also observed for measurements at $\theta=6^{\circ}$ in two orthogonal planes, for example, in the data previously used in an inertia-gravity wave case study by Thomas et al. (1992). Measurements with 2 or more pairs of symmetric beams in different azimuths could, therefore, be compared with model predictions of long-period wave instability (e.g. Andreassen et al., 1994; Fritts et al., 1994), and the associated vertical wave number spectrum might also be investigated. A radar system with a greater number of beam azimuth angles could show how the azimuth of largest power difference varies as 
the horizontal velocity vector of the long-period wave rotates with height.

\section{Conclusions}

Symmetric pairs of radar beams at zenith angles of $\pm 6^{\circ}$ and $\pm 12^{\circ}$ are used to measure wind velocity and radar echo power. Long-period wind structures, most commonly found in the lower stratosphere, are associated with imbalances between the echo powers of symmetric radar beams, with the peak power difference occurring at the height of the peak wind shear. The effect is strongest in conditions of high aspect sensitivity. A possible explanation is suggested in terms of tilted aspect-sensitive layers associated with shear instability of long-period waves, perhaps Kelvin-Helmholtz instability. The power-difference effect could be showing the early stages of processes that produce the thin turbulent layers often observed in the atmosphere.

Acknowledgements. The authors are indebted to the Meteorological Office for the award of a Gassiot Studentship to one of us (RMW). Figure 7a reprinted with permission from Nature (227, 260-263) Copyright (1970) Macmillan Magazines Limited.

Topical Editor L. Eymard thanks C. Sidi and M. Petitdidier for their help in evaluating this paper.

\section{References}

Andreassen, Ø., C. E. Wasberg, D. C. Fritts, and J. R. Isler, Gravity wave breaking in two and three dimensions. 1. Model description and comparison of two-dimensional evolutions, J. Geophys. Res., 99, 8095-8108, 1994

Axford, D. N., An observation of gravity waves in shear flow in the lower stratosphere, Q. J. R. Meteorol. Soc., 96, 273-286, 1970.

Axford, D. N., On an observation of turbulent waves on the tropopause surface. Q. J. R. Meteorol. Soc., 99, 438-449, 1973.

Bader, M. J., G. S. Forbes, J. R. Grant, R. B. E. Lilley, and A. J. Waters, Images in weather forecasting. A practical guide for interpreting satellite and radar imagery, Cambridge University Press, Section 3.2.2.3, 1995.

Bannon, J. K., Shear frequencies in the upper troposphere and lower stratosphere over England, Meteorol. Mag., 79, 161-165, 1950

Brown, W. O. J., S. Fukao, M. Yamamoto, and G. J. Fraser, Spaced antenna scattering and orientation measurements of the upper troposphere on the MU radar, J. Geomag. Geoelect., 47, 1231-1235, 1995.

Brown, W. O. J., S. Fukao, M. Yamamoto, Multiple antenna FDI observations on the MU radar, Proc. 7th Workshop on Tech. and Sci. Aspects of MST Radar, Ed. B. Edwards, SCOSTEP, Boulder, Colorado, USA, 384-387, 1996.

Browning, K. A., Structure of the atmosphere in the vicinity of large-amplitude Kelvin-Helmholtz billows, Q.J. R. Meteorol. Soc., 97, 283-299, 1971.

Browning, K. A., and C. D. Watkins, Observations of clear air turbulence by high power radar, Nature, 227, 260-263, 1970.

Browning, K. A., C. D. Watkins, J. R. Starr, and A. McPherson, Simultaneous measurements of clear air turbulence at the tropopause by high-power radar and instrumented aircraft, Nature, 228, 1065-1067, 1970.

Browning, K. A., J. R. Starr, and A. J. Whyman, Measurements of air motion in regions of clear air turbulence using high-power Doppler radar, Nature, 239, 267-269, 1972.
Cho, J. Y. N., Inertio-gravity wave parameter estimation from cross-spectral analysis, J. Geophys. Res., 100, 18727-18737, 1995.

Clodman, J., Anisotropic high-level turbulence, Q. J. R. Meteorol. Soc., 83, 116-120 (see also 84, 180-182), 1957.

Cornish, C. R., and M. F. Larsen, Observations of low-frequency inertia-gravity waves in the lower stratosphere over Arecibo, J. Atmos. Sci., 46, 2428-2439, 1989.

Dalaudier, F., C. Sidi, M. Crochet and J. Vernin, Direct evidence of "sheets" in the atmospheric temperature field, J. Atmos. Sci., 51, 237-248, 1994

Dutton, J. A., and H. A. Panofsky, Clear air turbulence: a mystery may be unfolding, Science, 167, 937-944, 1970.

Fritts, D. C., and P. K. Rastogi, Convective and dynamical instabilities due to gravity wave motions in the lower and middle atmosphere: theory and observations, Radio Sci., 20, 1247-1277, 1985.

Fritts, D. C., J. R. Isler, and Ø. Andreassen, Gravity-wave breaking in two and three dimensions. 2. Three dimensional evolution and instability structure, J. Geophys. Res., 99, 8109-8123, 1994.

Gage, K. S., Implications of tilting of stable layers on atmospheric measurements by clear-air Doppler radars, Preprints of $23 \mathrm{rd}$ Conf. on Radar Meteorology and Conf. on Cloud Physics, Sept. 22-26, 1986, Snowmass, Colo. American Meteorological Society, Boston, Mass., 30-33, 1986.

Gage, K. S., D. A. Carter and W. L. Ecklund, The effect of gravity waves on specular echoes observed by the Poker Flat MST radar, Geophys. Res. Lett., 8, 599-602, 1981.

Hicks, J. J., Radar observations of a gravitational wave in clear air near the tropopause associated with CAT, J. Appl. Meteorol., 8 , 627-633, 1969.

Hill, E. C. C., Breaking waves in cirrus cloud, Weather, 6, 286-287, 1951.

Hines, C. O., Tropopausal mountain waves over Arecibo: a case study, J. Atmos. Sci., 46, 476-488, 1989.

Hines, C. O., Comments on "Observations of low-frequency inertia-gravity waves in the lower stratosphere over Arecibo", J. Atmos. Sci., 52, 607-610, 1995.

Hooper, D., and L. Thomas, Aspect sensitivity of VHF scatterers in the troposphere and stratosphere from comparisons of powers in off-vertical beams, J. Atmos. Terr. Phys., 57, 655663, 1995.

Kilburn, C., S. Fukao, and M. Yamamoto, Extended period frequency domain interferometry observations at stratospheric and tropospheric heights, Radio Sci., 30, 1099-1109, 1995.

Klostermeyer, J., and R. Rüster, Further study of a jet streamgenerated Kelvin-Helmholtz Instability, J. Geophys. Res., 86, 6631-6637, 1981.

Larsen, M. F., Reply with comments on "Modulated mountain waves", J. Atmos. Sci., 52, 611-612, 1995.

Larsen, M. F., and J. Röttger, VHF radar measurements of inbeam incidence angles and associated vertical-beam radial velocity corrections, J. Atmos. Ocean. Tech., 8, 477-490, 1991.

Luce, H., M. Crochet, F. Dalaudier, and C. Sidi, Interpretation of VHF ST radar vertical echoes from in situ temperature sheet observations, Radio Sci., 30, 1003-1025, 1995.

Ludlam, F. H., Characteristics of billow clouds and their relation to clear-air turbulence, Q. J. R. Meteorol. Soc., 93, 419-435, 1967.

O'Sullivan, D. and T. J. Dunkerton Generation of inertia-gravity waves in a simulated life cycle of baroclinic instability, J. Atmos. Sci., 52, 3695-3716, 1995.

Palmer, R. D., M. F. Larsen, R. F. Woodman, S. Fukao, M. Yamamoto, T. Tsuda, and S. Kato, VHF radar interferometry measurements of vertical velocity and the effect of tilted refractivity surfaces on standard Doppler measurements, Radio Sci., 26, 417-427, 1991.

Palmer, R. D., M. F. Larsen, E. L. Sheppard, S. Fukao, M. Yamamoto, T. Tsuda, and S. Kato, Poststatistic steering wind estimation in the troposphere and lower stratosphere, Radio Sci., 28, 261-271, 1993.

Pfister, L., W. Starr, R. Craig, M. Loewenstein, and M. Legg, Small-scale motions observed by aircraft in the tropical lower 
stratosphere: evidence for mixing and its relationship to largescale flows, J. Atmos. Sci., 43, 3210-3225, 1986.

Reid, I. M., R. Rüster, and G. Schmidt VHF radar observations of cat's-eye-like structures at mesospheric heights, Nature, 327, 43-45, 1987.

Reiter, E. R., and A. Nania, Jet-stream structure and clear-air turbulence (CAT), J. Appl. Meteorol., 3, 247-259, 1964.

Roach, W. T., Some aircraft reports of high-level turbulence, Meteorol. Mag., 98, 65-78, 1969.

Röttger, J., and G. Schmidt, High-resolution VHF radar sounding of the troposphere and stratosphere, IEEE Trans. Geosci. Electr., GE17, 182-189, 1979.

Röttger, J., C. H. Liu, J. K. Chao, A. J. Chen, C. J. Pan, and I-J. Fu, Spatial interferometer measurements with the Chung-Li VHF radar, Radio Sci., 25, 503-515, 1990.

Sato, K., A statistical study of the structure, saturation and sources of inertio-gravity waves in the lower stratosphere observed with the MU radar, J. Atmos. Terr. Phys., 56, 755-774, 1994.

Sato, T., and R. F. Woodman, Fine altitude resolution observations of stratospheric turbulent layers by the Arecibo $430 \mathrm{MHz}$ radar, J. Atmos. Sci., 39, 2546-2552, 1982.

Schilling, V. K., and U. Janssen, Particle dispersion due to dynamical instabilities in the lower stratosphere, Beitr. Atmos. Phys., 65, 259-273, 1992.

Thomas, L., I. T. Prichard, and I. Astin Radar observations of an inertia-gravity wave in the troposphere and lower stratosphere, Ann. Geophysicae., 10, 690-697, 1992.

Thompson, R. O. R. Y., Observation of inertial waves in the stratosphere, Q. J. R. Meteorol. Soc., 104, 691-698, 1978.

Tsuda, T., K. Hirose, S. Kato, and M. P. Sulzer, Some findings on correlation between the stratospheric echo power and the wind shear observed by the Arecibo UHF radar, Radio Sci., 20, 1503-1508, 1985.

Tsuda, T., W. E. Gordon, and H. Saito, Azimuth angle variations of specular reflection echoes in the lower atmosphere observed with the MU radar, J. Atmos. Terr. Phys., in press, 1997a.

Tsuda, T., T. E. VanZandt, and H. Saito Zenith-angle dependence of VHF specular reflection echoes in the lower atmosphere, J. Atmos. Terr. Phys., in press, $1997 \mathrm{~b}$.

Van Baelen, J. S., A. D. Richmond, T. Tsuda, S. K. Avery, S. Kato, S. Fukao, and M. Yamamoto, Radar interferometry technique and anisotropy of the echo power distribution: first results, Radio Sci., 26, 1315-1326, 1991.

Worthington, R. M., and L. Thomas, Radar measurements of critical-layer absorption in mountain waves, $Q . J$. R. Meteorol. Soc., 122, 1263-1282, 1996a.

Worthington, R. M., and L. Thomas, The measurement of gravitywave momentum flux in the lower atmosphere using VHF radar, Radio Sci., 31, 1501-1517, 1996 b.

Yamanaka, M. D., S. Ogino, S. Kondo, T. Shimomai, S. Fukao, Y. Shibagaki, Y. Maekawa, and I. Takayabu, Inertio-gravity waves and subtropical multiple tropopauses: vertical wavenumber spectra of wind and temperature observed by the MU radar, radiosondes and operational rawinsonde network, J. Atmos. Terr. Phys., 58, 785-805, 1996.

Yoe, J. G., P. Czechowsky, R. Rüster, and G. Schmidt, Spatial variability of the aspect sensitivity of VHF radar echoes in the troposphere and lower stratosphere during jet stream passages. Ann. Geophysicae, 12, 733-745, 1994.

Young, J. R. C., Breaking gravity waves on a jet stream over the North Pacific, Weather, 26, 306-307, 1971. 